\title{
ОРГАНИЗАЦИЯ ЦИКЛОВ ПОВЫШЕНИЯ КВАЛИФИКАЦИИ В СИСТЕМЕ НЕПРЕРЫВНОГО МЕДИЦИНСКОГО ОБРАЗОВАНИЯ НА КАФЕДРЕ ТЕРАПИИ ИМ. ПРОФ. А.И. ДЯДЫКА ФИПО ГОО ВПО ДОННМУ ИМ. М.ГОРЬКОГО - НАЧАЛО
}

Непрерывное медицинское образование (НМО) - это система последипломного образования, обеспечивающая непрерывное совершенствование знаний и навыков, умений в течение всей профессиональной жизни врача, а также постоянное повышение профессионального уровня и расширение профессиональных компетенций [8].

Система НMO внедряется, прежде всего, с целью повышения качества последипломной подготовки врачей и провизоров $[4,5]$.

Вопрос о НMO имеет корни в странах Западной Европы и США, где достаточно давно действует система CME - Continuous Medical Education. НMO является аналогом принятой в развитых странах Европы и Северной Америки системы CME $[10,12]$. В Российской Федерации система НМО в качестве ведущего варианта последипломного образования уже принята в течение нескольких последних лет.

Концепция образования за последние годы существенно изменилась. В начале XX века обновление знаний происходило каждые 20-30 лет, и общество не так остро чувствовало недостаток новейших знаний при сохранении неизменной системы образования.

Сейчас знания обновляются, по мнению экспертов, на 15\% в год, т.е. полностью каждые 6 лет. И традиционно существующие системы базового образования не успевают за увеличивающимся потоком научной информации.

Пока система и технологии образования будут отставать от темпов обновления знаний, профессиональная жизнь врачей может быть не столь продуктивной, как это возможно [2, 3]. Все это указывает на значимость системы непрерывного образования в течение всей жизни врача, как ведущего фактора его профессионального развития. Непрерывное образование делает его труд более продуктивным и совмещается с основным видом деятельности в сфере здравоохранения.

Для ДНР внедрение системы НМО имеет особое значение в связи с острой нехваткой врачей и сложностями обучения на циклах повышения квалификации в течение месяца (отсутствие замены на рабочих местах) [6].

Главная цель обучения с внедрением НMO не только профессиональный, но и личностный рост специалиста, т.е. не только то, что должен знать и уметь обучаемый к концу курса обучения, но и что он должен делать иначе в результате полученных знаний и умений [11].

Содержание НМО в ДНР реализуется в дополнительных профессиональных образовательных программах повышения квалификации, которые разрабатываются на основе государственных требований (стандартов) к содержанию и уровню подготовки специалистов соответствующей специальности и квалификации.

Внедрение НМО включает в себя:

- переход на непрерывное обучение медицинского работника (в течение всего календарного года, отдельными циклами или курсами, путем прохождения отдельных учебных мероприятий) на протяжении всей его профессиональной жизни;

- применение в обучении дистанционных образовательных технологий и электронного обучения с учетом передового опыта в мировой образовательной практике;

- формирование учебных программ с учетом наиболее актуальных проблем практического здравоохранения;

(c) Г.А. Игнатенко, А.Э. Багрий, А.В. Ващенко,

Г.Г. Тарадин, В.Б. Гнилицкая, А.Л. Христуленко,

О.А. Приколота, И.И. Здиховская, 2020

(c) Университетская Клиника, 2020 
- сетевое взаимодействие образовательных и профессиональных организаций в интересах внедрения лучших образовательных практик.

В настоящее время в Донецком национальном медицинском университете имени М.Горького начат перевод обучения курсантов (врачей и провизоров) на систему НМО, Основные принципы НМО регламентируются Приказом N 616 от 18 мая 2018 г. МЗ ДНР «Об утверждении Порядка организации непрерывного медицинского образования специалистов с высшим медицинским и фармацевтическим образованием», изменения приказа №1420 от 4 сентября 2018 г.

Созданию Приказа N 616 предшествовало длительное и подробное обсуждение с участием ректората ВУЗа и специалистов МЗ ДНР, тем не менее, ряд вопросов еще будет требовать ответа, а некоторые положения системы НМО - дополнительной разработки и, возможно, коррекции.

В ДНР до 2025 г. планируется постепенный переход к аккредитации специалистов с высшим медицинским образованием. Чтобы все участники системы здравоохранения могли последовательно и комфортно перейти к новой системе НMO и системе аккредитации специалистов, вводится переходный период. В переходный период (с 2018 по 2024 гг. включительно) врачи получают сертификаты и по существующей системе, и по модели НМО. В настоящее время в ДНР в системе НМО повышают квалификацию врачи следующих специальностей: «Терапия», «Общая практика - семейная медицина», «Неонатология», «Педиатрия», «Урология», «Травматология», «Дерматовенерология». С 2018 г. после прохождения аттестации, врачи этих специальностей переходят к обучению в системе НМО и должны накапливать по 50 кредитов в год. Для последующей аттестации (аккредитации) по специальности врач должен накопить за 5 лет 250 кредитов.

С целью реализации программ НMO и учета образовательной активности специалистов определяются принципы набора и учета условных единиц образовательной активности, именуемыми «зачетными единицами трудоемкости», а также порядок допуска специалистов к итоговой аттестации: 1 ЗЕТ соответствует 1 академическому часу, в которых оценивается основная учебная и дополнительная образовательная деятельность специалистов $[8,9]$.

Применительно к специальности «Терапия» этим Приказом (и утвержденным на его основании соответствующим Порядком) предусмотрено, что терапевты, получившие сертификат специалиста или свидетельство об аттестации спе- циалиста после 1 января 2017 года, проходят обучение только в рамках системы НМО.

Как и ранее, проведение итоговой аттестации предусмотрено с интервалом в 5 лет.

Обучение работника в рамках НМО выполняется не с проведением предаттестационного цикла 1 раз в 5 лет (как это было ранее), а на постоянной основе (ежегодные недельные циклы повышения квалификации на кафедре ФИПО - 36 ЗЕТ ежегодно и дополнительно в течение года другие формы образовательной деятельности - 14 3ЕТ) [1].

Дополнительная образовательная деятельность представлена:

- участием специалистов в освоении образовательных модулей тематического усовершенствования (лекциях, семинарах, тренингах, мастер-классах, в т.ч. проводимых с применением дистанционных образовательных технологий и электронного обучения), вне основной учебной деятельности.

- участием специалистов в работе республиканских, международных научных, научнопрактических мероприятий (съездов, симпозиумов, конференций).

- внедрение в сферу здравоохранения новых медицинских технологий, современных методов лечения и реабилитации пациентов, методов диагностики и профилактики заболеваний.

- получением патента на полезную модель, рационализаторское предложение.

- публикацией статей и (или) тезисов в сборниках научных работ в профессиональных медицинских или фармацевтических журналах, изданием клинического руководства, монографии, учебника, учебного или учебно-методического пособия по основным направлениям специальности.

- подготовкой и защитой диссертации на соискание ученой степени кандидата (доктора) медицинских (фармацевтических) наук.

Основная учебная деятельность осуществляется путем обучения по программам повышения квалификации по специальности, указанной в сертификате специалиста, дипломе о дополнительном профессиональном образовании (в том числе с применением дистанционных образовательных технологий и электронного обучения).

Основная учебная деятельность распределяется в течение первых 4 х лет с общей трудоемкостью 144 ЗЕТ по 36 ЗЕТ ежегодно.

В один из годов пятилетнего периода НМО специалист проходит цикл тематического усовершенствования трудоемкостью 72 3ЕT.

Учет ЗЕТ осуществляется за 5 лет, предшествующих аттестации. 
Необходимое количество ЗЕТ, набранных специалистами за пятилетний цикл для получения допуска к итоговой аттестации, должно составлять не менее 250.

Руководитель подразделения дополнительного профессионального образования или его заместитель не позднее, чем за 2 недели до итоговой аттестации проводят проверку соответствия листа образовательной активности специалиста, участвующего в системе НМО, настоящему Порядку и принимают решение о его допуске к итоговой аттестации.

Основанием для отказа в допуске к итоговой аттестации являются: недостоверная информация о набранных ЗЕТ, недостаточное количество 3ЕТ, набранных за основную учебную деятельность, несоответствие основной учебной деятельности наименованию специальности.

После успешной сдачи итоговой аттестации в ГОО ВПО «Донецкий национальный медицинский университет им. М.Горького» специалисту выдается документ установленного образца.

Присвоение либо подтверждение квалификационной категории специалистов проводится Аттестационной комиссией Министерства здравоохранения Донецкой Народной Республики в соответствии с действующим законодательством.

Обучение в системе НМО для специалистов, находящихся в отпуске по беременности и родам, по уходу за ребенком или при длительной утрате трудоспособности, продлевается на срок, связанный с продолжительностью данного обстоятельства.

Качество подготовки специалистов в значительной мере определяется качеством преподавания и проведения занятий. На это направлены силы всех кафедральных коллективов. Система отбора преподавателей предусматривает не только обязательное наличие соответствующей специализации и высокой квалификации, но также участие в работе международных, всероссийских, республиканских конференций и обучающих семинаров, участие в научно-исследовательской работе (НИР), производственные стажировки и др.

Научно-педагогические работники клинических кафедр также участвуют в системе НMO с обязательным прохождением циклов повышения квалификации (с общей трудоемкостью 144 ЗЕТ - по 36 ЗЕТ ежегодно),

Для методологического обеспечения внедрения системы НМО сотрудники кафедры терапии ФИПО разрабатывают и внедряют образовательные мероприятия с использованием:

1) интернет-портала НMO;
2) интерактивных образовательных модулей по соответствующей специальности;

3) дистанционных образовательных технологий и электронного обучения.

Форма освоения и содержание обучения определяется образовательной программой повышения квалификации, разрабатываемой образовательной организацией.

Коллектив кафедры терапии ФИПО начал проводить обучение в системе НМО с 1 сентября 2018 г. Были подготовлены и утверждены рабочие программы и учебные планы по всем модулям обучения; методические указания для обучающихся и методические рекомендации для преподавателей, совместно с сотрудниками МЗ ДНР проводилась работа по своевременному информированию руководителей здравоохранения о новых принципах повышения квалификации с целью упорядочения набора врачей на циклы повышения квалификации в системе НМО. Формируется «база данных» слушателей ФИПО различных специальностей.

С сентября 2018 года по декабрь 2019 года проведено 22 цикла НМО по специальности «Терапия» (Модуль 1 - 15 циклов и Модуль 2 - 7 циклов).

Всего обучалось 329 человек (Модуль 1 - 244 курсанта, Модуль 2 - 85 курсантов). Из них 222 человека работает в поликлинике, 107 - в стационаре. Распределение обучающихся по врачебным категориям следующее: 68\% врачей имеют высшую категорию, 15\% - первую категорию, 6\% - вторую категорию, $11 \%$ - без категории.

На кафедре терапии им. проф. А.И. Дядыка ФИПО прилагаются усилия, чтобы максимально сохранить время обучения в 1-й и последние дни. 1-й день начинается с регистрации на кафедре. Далее проводится собеседование с целью определения исходного уровня знаний, дается информация о НМО и плане обучения по годам, после чего учебный день проходит согласно программе. В конце 1-ого дня обсуждаются пожелания по дальнейшей работе (предпочтения тем занятий), вопросы работы с информационной образовательной средой, электронными пособиями, печатными материалами кафедры. В последний день проводится занятие согласно учебной программе, учитываются предложения по улучшению организации цикла, проводится контроль знаний в форме собеседования/компьютерного тестирования.

Согласно разработанным рабочим программам обучение проходит по следующей схеме: в 1-й год обучения Модуль 1, во 2-й год обучения - Модуль 2, в 3-й год обучения - Модуль 3, в 4-й год обучения - курсы тематического усовершенствования (72 часа), в 5-й год обучения - Модуль 
4, после чего предусмотрена сдача квалификационного экзамена.

При проведении НМО кафедра столкнулась определенными сложностями, среди которых можно выделить следующие:

- сложность набора курсантов (недостаточная готовность руководителей лечебных учреждений направить на обучение сотрудников в связи с дефицитом кадров);

- недостаточная согласованность учебнопроизводственного плана с лечебнопрофилактическими учреждениями.

Врачи также столкнулись с некоторыми сложностями при переходе к системе НMO, обусловленными, в основном, ограниченной возможностью набора дополнительных 3ЕТ, которые перечислены ниже:

- в связи с недостатком кадров в ЛПУ не все имеют возможность посетить курсы тематического усовершенствования, научнопрактические конференции, дни специалиста и т.д.;

- расходы на дорогу;

- тревога в отношении «набора 3ET» (не могут оставить рабочее место и посетить конференции, несовершенный балльник);

- не до конца разработанные вопросы дистанционного обучения.

На кафедре терапии им. проф. А.И. Дядыка ФИПО проведено анкетирование обучающихся на циклах НМО в 2018 и 2019 годах. Проанализировано 222 анкеты за 2018 год и 2019 год. Согласно данным опроса врачей, проходивших курсы НMO 2018 и 2019 гг., навыками работы за компьютером владеют лишь 69 \% и 78\% врачей соответственно, что нередко связано с пожилым возрастом слушателей. Только 29\% и 30\% соответственно врачей имеют опыт работы с системами дистанционного обучения (вебинары и др.). 7\% не уверены в его необходимости. 70\% (2018 г.) и 85\% (2019 г.) хотели бы иметь возможность дистанционного обучения, особенно, если дистанционное обучение с использованием информационно-образовательной среды позволит получать дополнительные баллы. Тем не менее, 20,5\% (2018 г.) и 6\% (2019 г) врачей остаются против внедрения дистанционного обучения, 11,3\% (2018 г.), 4\% (2019 г.) не уверены в целесообразности его организации, 68,2\% (2018 г.) и 90\% (2019 г) считают это необходимым.

Информацию о необходимости прохождения курсов НМО в 2018 и 2019 годах врачи получают от: отдела кадров своих лечебных учреждений (53\%), деканата ФИПО (9\%), МЗ ДНР (7\%), кафедры терапии ФИПО (31\%).

По данным анкетирования в 2018 году 57\% врачей предпочитают собеседования для кон- троля знаний, 36\% - тестовый контроль, 7\% высказали предложение не проводить контроль знаний вообще. В 2019 году 84\% опрошенных не имеют предложений по проведению контроля знаний, лишь 10\% опрошенных желают проходить тестирование.

У $41 \%$ врачей, обучавшихся на курсах НМО в 2018 году, и у 66\% в 2019 году возникают трудности с посещением конференций, дней специалиста и др. Это обусловлено недостатком кадров в ЛПУ, большим объемом работы в стационаре, учебным процессом (преподаватели), а также отсутствием информации и проблемами с оповещением о проведении мероприятий.

Проанализировав вышеприведенные данные можно выделить основные проблемы внедрения дистанционного обучения:

1. недостаток владения навыком работы за компьютером, что нередко связано с возрастным фактором и недостаточной компьютерной грамотностью,

2. отсутствие опыта работы с системами дистанционного обучения,

3. в отдельных случаях - нежелание обучаться дистанционно, даже если это позволит получить дополнительные баллы (ЗЕТ).

Врачи высказали свои пожелания по начислению дополнительных баллов (ЗЕТ): дополнительные лекции, циклы тематического усовершенствования (8\%), лекции по месту работы врачей (5\%), оценивание конференций большим количеством баллов (5\%), дистанционное обучение (5\%).

Постулируется, что целью внедрения системы НМО является повышение качества подготовки врачей/провизоров. Ряд специалистов высшего дополнительного профессионального образования, однако, придерживаются более сдержанной позиции. Так, имеются сомнения в сохранении необходимой преемственности между отдельными длящимися по 1 неделе ежегодными циклами повышения квалификации. Высказывается также точка зрения о том, что система более адаптирована под страны, обладающие значительными ресурсами программ самостоятельного обучения (в т.ч. дистанционного), а также предоставляющие большие возможности участия в конференциях и иных внеаудиторных образовательных программах [2, 7].

Качество учебного процесса в значительной мере определяется состоянием материальнотехнической базы кафедры и лечебных учреждений. В связи с этим требуется постоянное ее обновление и модернизация с целью соответствия современному уровню развития науки и техники; разработка и создание самых современных материалов для информационно- 
образовательной среды, контроль за обеспеченностью обучающихся учебной литературой и методическими разработками по соответствующим разделам и своевременным их обновлением.

Безусловно, эффективность системы НМО требует проверки на практике. Однако, опыт обучения врачей-терапевтов в системе НМО в 2018 и 2019 гг. показал работоспособность этой системы, что нашло отклики в результатах анкетирования врачей-курсантов терапевтов. Удовлетворенность врачей качеством лекций и практических занятий Модуля 1 составила 95,5\%, Модуля 2 - 94\%.
Коллектив кафедры терапии им проф. А.И. Дядыка ФИПО будет продолжать работу по успешной реализации НМО и с этой целью всем участникам программ НMO (от самих врачей/ провизоров и кафедральных коллективов до администрации органов здравоохранения, руководства образовательных организаций, участвующих в НМО, а также сотрудников МЗ ДНР) требуется приложить большие усилия. Крайне важно обеспечить необходимое взаимодействие между перечисленными участниками НМО, без чего переход на новый вариант обучения не будет успешным.

Г.А. Игнатенко, А.Э. Багрий, А.В. Ващенко, Г.Г. Тарадин, В.Б. Гнилицкая,

А.Л. Христуленко, О.А. Приколота, И.И. Здиховская

ГОО ВПО «Донецкий национальный медицинский университет имени М. Горького», Донецк

\section{ОРГАНИЗАЦИЯ ЦИКЛОВ ПОВЫШЕНИЯ КВАЛИФИКАЦИИ В СИСТЕМЕ НЕПРЕРЫВНОГО МЕДИЦИНСКОГО ОБРАЗОВАНИЯ НА КАФЕДРЕ ТЕРАПИИ ИМ. ПРОФ. А.И. ДЯДЫКА ФИПО ГОО ВПО ДОННМУ ИМ. М.ГОРЬКОГО - НАЧАЛО}

Система непрерывного медицинского образования обеспечивает непрерывное совершенствование знаний и навыков, умений в течение всей профессиональной жизни врача, постоянное повышение профессионального уровня и расширение профессиональных компетенций. В статье рассматриваются цели, задачи, пути реализации вышеуказан- ной системы последипломного образования. Описаны основные принципы обсуждаемой системы, этапы ее внедрения на кафедре терапии им. проф. А.И. Дядыка ФИПО.

Ключевые слова: система непрерывного медицинского образования, циклы повышения квалификации

\section{G.A. Ignatenko, A.E. Bagriy, A.V. Vaschenko, G.G. Taradin, V.B. Gnilitskaya,} A.L. Khristulenko, O.A. Prikolota, I.I. Zdykhovska

SEI HPE «M. Gorky Donetsk National Medical University», Donetsk

\section{ORGANIZATION OF THE CYCLES OF INCREASING THE QUALIFICATIONS IN THE SYSTEM OF CONTINUOUS MEDICAL EDUCATION IN THE DEPARTMENT OF THE THERAPY OF FIPE DONNMU NAMED AFTER M.GORKY - BEGINNING}

The system of continuous medical education ensures continuous improvement of knowledge and skills throughout the professional life of the doctor, as well as continuous professional development and expansion of professional competencies. The article examines the goals, objectives, ways of implementing the above-men- tioned system of postgraduate education. The main principles of the system under discussion, the stages of its implementation at the FIPE Department of DONNMU named after M. GORKY, are described.

Key words: system of continuous medical education, advanced training courses.

\section{ЛИТЕРАТУРА}

1. Абакаров С.И., Вагнер В.Д., Сорокин Д.В. и др. Балльнонакопительная система сертификации как фактор совершенствования непрерывного профессионального образования врачей-стоматологов. Институт стоматологии. 2011; 4: 14-15.

2. Андреев А.А. Становление и развитие дистанционного обучения в России. Высш. образование в России. 2012; 10: $107-111$.

\section{REFERENCES}

1. Abakarov S.I., Vagner V.D., Sorokin D.V. i dr. Ball'nonakopitel'naya sistema sertifikatsii kak faktor sovershenstvovaniya nepreryvnogo professional'nogo obrazovaniya vrachei-stomatologov [Ball-cumulative certification system as a factor of improving the continuous professional education of dentists]. Institut stomatologii. 2011; 4: 1415 (in Russian).

2. Andreev A.A. Stanovlenie i razvitie distantsionnogo obu- 
3. Буянкина Р.Г., Соколова О.Р. Опыт внедрения интернеттехнологий дистанционного обучения в подготовке детских стоматологов. Cathedra. 2016; 57: 62-65.

4. Ибрагимов Т.И. Совершенствование системы последипломного образования врачей-стоматологов. Маэстро стоматологии. 2012; 1 (45): 10-12.

5. Найговзина Н.Б., Лучинский А.В. Непрерывное профессиональное образование врачей-стоматологов в Российской Федерации. Российская стоматология. 2015; 8 (3): 48-51. DOI: 10.17116/rosstomat20158348-51

6. Кудрявая Н.В., Уколова Е.М., Смирнова Н.Б. и др. Педагогика в медицине: Учебное пособие для студ. учреждений высш. проф. образования. М.: «Академия»; 2012. 320.

7. Белогурова В.А. Научная организация учебного процесса. М.: ГЭОТАР-Медиа; 2010. URL: http://www. studmedlib.ru/book/ISBN9785970414965.html (дата обращения: 16.12.2019).

8. Бим-Бад Б.М. Педагогический энциклопедический словарь. М.: Большая Российская энциклопедия; 2008. 528.

9. Агафонов Б.В. Опыт организации непрерывного профессионального образования для врачей общей практики Московской области. Земский врач. 2011; 1: 3942.

10. Клевно В.А., Кучук С.А. Роль медицинской организации в НМО на примере ГБУЗ МО «Бюро СМЭ». Медицинское образование и профессиональное развитие. 2014; 3: 68-70.

11. Пальцев М.А. Проблемы развития высшего и послевузовского медицинского и фармацевтического образования. Ремедиум. 2008; 7: 6-8.

12. Пивень Д.В. О новых тенденциях в системе медицинского последипломного образования и необходимости их развития. Менеджер здравоохранения. 2008; 4: 3339. cheniya v Rossii [Formation and development of distance learning in Russia]. Vyssh. obrazovanie v Rossii. 2012; 10: 107-111 (in Russian).

3. Buyankina R.G., Sokolova O.R. Opyt vnedreniya internettekhnologii distantsionnogo obucheniya $\mathrm{v}$ podgotovke detskikh stomatologov [Experience of introduction of Internet technologies of distance learning in the preparation of children's dentists]. Cathedra. 2016; 57: 62-65 (in Russian).

4. Ibragimov T.I. Sovershenstvovanie sistemy poslediplomnogo obrazovaniya vrachei-stomatologov [Perfection of the system of postgraduate education of dentists]. Maestro stomatologii. 2012; 1 (45): 10-12 (in Russian).

5. Naigovzina N.B., Luchinskii A.V. Nepreryvnoe professional'noe obrazovanie vrachei-stomatologov $\mathrm{v}$ Rossiiskoi Federatsii [Continuous professional education of dentists in the Russian Federation]. Rossiiskaya stomatologiya. 2015; 8 (3): 48-51. DOI: 10.17116/rosstomat20158348-51 (in Russian).

6. Kudryavaya N.V., Ukolova E.M., Smirnova N.B. i dr. Pedagogika v meditsine: Uchebnoe posobie dlya stud. uchrezhdenii vyssh. prof. obrazovaniya [Pedagogy in medicine: textbook for student institutions of higher professional education]. M.: «Akademiya»; 2012. 320 (in Russian).

7. Belogurova V.A. Nauchnaya organizatsiya uchebnogo protsessa [Scientific organization of the educational process]. Moscow: GEOTAR-Media; 2010. URL: http:// www.studmedlib.ru/book/ISBN9785970414965.html (data obrashcheniya: 16.12.2019) (in Russian).

8. Bim-Bad B.M. Pedagogicheskii entsiklopedicheskii slovar' [Pedagogical encyclopedic dictionary]. Moscow: Bol'shaya Rossiiskaya entsiklopediya; 2008. 528 (in Russian).

9. Agafonov B.V. Opyt organizatsii nepreryvnogo professional'nogo obrazovaniya dlya vrachei obshchei praktiki Moskovskoi oblasti [Experience in organizing continuing professional education for general practitioners in the Moscow Region]. Zemskii vrach. 2011; 1: 3942 (in Russian).

10. Klevno V.A., Kuchuk S.A. Rol' meditsinskoi organizatsii v NMO na primere GBUZ MO «Byuro SME» [The role of the medical organization in the NMI on the example of the SBE of the Ministry of Defense «Bureau of SMEs»]. Medical education and professional development. 2014; 3: 6870 (in Russian).

11. Pal'tsev M.A. Problemy razvitiya vysshego i poslevuzovskogo meditsinskogo i farmatsevticheskogo obrazovaniya [Problems of development of higher and postgraduate medical and pharmaceutical education]. Remedium. 2008; 7: 6-8 (in Russian).

12. Piven' D.V. O novykh tendentsiyakh v sisteme meditsinskogo poslediplomnogo obrazovaniya i neobkhodimosti ikh razvitiya [On new trends in the system of medical postgraduate education and the need for their development]. Healthcare manager. 2008; 4: 33-39 (in Russian). 